
VÁRIA

VARIA 


\section{De pive a pibe chorro. El uso de pibe en el español rioplatense}

Malena Velarde

Recebido em: 22 de janeiro de 2020

Aceito em: 12 de maio de 2020
Licenciada en Letras por la Universidad de Buenos Aires y estudiante de la maestría Literaturas de América Latina de la Universidad Nacional de San Martín. Dirige el Programa Memorias Recientes para la escritura de testimonios históricos dependiente de la Secretaría de Extensión Universitaria y Bienestar Estudiantil de la Universidad de Buenos Aires. Contato: malevelarde@smail.com Argentina 
PALABRAS CLAVE: pibe; lunfardo; variedad lingüística.

KEYWORDS: pibe; lunfardo; language variety.
Resumen: La etimología de la palabra pibe, atestiguada por primera vez en el Río de la Plata en 1894 en El idioma del delito por Antonio Dellepiane, ha sido objeto de controversia: Lantírrasis española o italianismo jergal? Corominas refuta su origen italiano ya que considera que considera que esta voz no se restringe al lunfardo sino que forma parte del habla general. Sin embargo, la extensión de este término no es contradictoria con su uso como lunfardismo y su posible etimología del italiano. El análisis de la presencia de pibe en diccionarios, textos literarios, medios gráficos y canciones permite observar que la tendencia ampliatoria de este término coincide con la pérdida del matiz peyorativo que inicialmente se le atribuía cuando era empleado para designar a jóvenes, a la vez que exhibe su productividad para integrarse, en la actualidad, a la variedad tumbera y para adquirir nuevos usos en el habla coloquial.

Abstract: The etymology of the word pibe, witnessed for the first time in the Rio de la Plata in 1894 in The Language of Crime by Antonio Dellepiane, has been the subject of controversy: Spanish antiphrasis or slang italianism?. Corominas refutes the link to this jargon since pibe is a word widely used and not only restricted to Lunfardo speakers. However, the extension of this word is not contradictory to its use as lunfardism and its Italian etymology. The analysis of the presence of pibe in lexicosraphical works and in literary texts, graphic media and songs allows us to observe that the broadening trend of this word coincides with the loss of the pejorative nuance that was initially attributed to it when it was employed to designate young people. This presence also exhibits its productivity to integrate the current tumbero slang and to acquire new uses in colloquial speech. 
En el Diccionario crítico etimológico. Castellano e hispánico, Joan Corominas postula que pibe deriva de la palabra espańola pebete, empleada para designar 'pasta aromática'. Esta palabra, a su vez, sería un catalanismo en -et del S. XVI, proveniente de la forma pevet, cuyo testimonio más antiguo remonta al Spill de Jaume Roig del año 1460 en donde se emplea para referirse a 'sustancia aromática'. Corominas señala que, en catalán, pevet se emplea también para referirse al 'pebetero', es decir, un candelero en donde se quemaban los pebetes. Por su función y forma, este elemento podría haber sido nombrado como 'pie pequeño', es decir, peuet, disminutivo de peu ('pie'). Respecto a su fonología, se ignora si la pronunciación corresponde a peuet o pevet puesto que en la época de la cual proviene la forma más antigua atestiguada no se distinguía gráficamente entre la $u$ y la $v$ intervocálicas.

En América, plantea Corominas, su empleo corresponde a la antífrasis de pebete y designaría un objeto maloliente. En Argentina y Uruguay, partiendo de esta antífrasis se pasó a "nińo de mantillas" (Corominas, 1954, 445) para hablar de un niño pequeño que por su condición económica no presenta higiene.

Esta etimología discute con la planteada por Wagner en 1928, quien también pone pibe en relación con pebete aunque no para designar su origen. Este autor señala que estas dos voces en el uso rioplatense no corresponden a la palabra española para designar el manojo de incienso, sino que se trataría de un término derivado del genovés pivetto, una variante menos frecuente de pivel 'mozo, joven'. Pibe, por otra parte, estaría en relación a 
pivo y pivello, puesto que estas son las denominaciones más comunes para referirse a 'pilluelo' (Wagner, 1928, 194) dentro de los distintos dialectos del italiano. Para defender su postura, Wagner resalta que pibe y pebete son empleadas únicamente en los países del Río de la Plata y que no es posible encontrar voces similares en otros países de habla hispana.

En 1936, Ambruzzi -a propósito de la entrada publicada en el Diccionario de Americanismos de Augusto Malaret- seńala que pivetto no es una voz frecuente en los dialectos italianos y solamente pivo y pivello están suficientemente extendidos en el lombardo y en el emiliano. Respecto a estas voces, Ambruzzi conjetura que podrían estar relacionadas con pibe pero no con pebete. Sin embargo, indica que no hay evidencias suficientes (Ambruzzi, $1936,68)$ puesto que pivel no indicaría 'nińo' sino ‘joven', y pivo ya sería una forma en desuso para principios de siglo XX.

Corominas cita los argumentos de Ambruzzi para refutar el origen italiano basándose en la dificultad de encontrar un antecedente posible para pibe y pebete. En su artículo se señala que si tomáramos pivetto, pivo o pivello encontraríamos problemas para establecer la evolución desde el punto de vista fonético, ya que en ese caso la forma resultante tendría que haber sido * pibo. Una salvedad podría ser que en primer lugar se haya introducido piba, pero Corominas descarta esta hipótesis alegando que piba es menos frecuente que pibe.

Finalmente, para refutar pebete como un italianismo jergal, Corominas plantea como alternativa que esta voz habría ingresado al Río de la Plata a través del Brasil: "partiendo de la variante aportuguesada pibete, que 
Dellepiane registra en el sentido de 'niño', tomándola por un disminutivo, se sacó un seudo-primitivo pibe, que en consecuencia natural designe a personas de más edad que las expresadas por pebete.” (Corominas, 1954, 448). Para Beatriz Gómez Pablos, el origen italiano resulta una explicación "más transparente que el castellano” (Gómez Pablos, 1999, 154). En su artículo “¿Un lunfardismo en Canarias? Algunas observaciones sobre la etimología de pibe" señala que esta voz es un lunfardismo a partir del préstamo genovés pivetto que, junto con sus equivalentes en otros dialectos, habría circulado a fines del siglo XIX cristalizándose en pibe. Destaca, en este sentido, el registro de esta voz en el "Diccionario Lunfardo - Español" de El idioma del delito de Dellepiane con distintas variantes:

En El idioma del delito Dellepiane no se limita a definir la voz pive ("muchacho, menor de edad, pilluelo. Lo mismo que quillete"), sino que además expone diferentes variantes: pive, piver, pebe, pibete o pebete. Esto atestigua que a finales de siglo pasado circulaban en Buenos Aires diversas formas que con el tiempo se fueron perdiendo hasta cristalizarse en dos: pibe y pebete. Esta inseguridad y a la vez similitud de las expresiones hace pensar precisamente en un período en el que conviven en Argentina inmigrantes italianos de diferentes regiones. Cada uno conserva su habla característica al tiempo que estas hablas se van contaminando entre sí y el español hasta adoptar una forma única. Desde Argentina, así opina Wagner, se extendería a los países vecinos (Gómez Pablos, 1999, 152).

El Diccionario de voces lunfardas rioplatenses de Mario Teruggi (1998), el Diccionario etimológico del lunfardo (1998) de Oscar Conde y el Nuevo diccionario del lunfardo de José Gobello (1999) retoman pivetto y pivello como etimología para pibe. Autoras como Fontanella de Weimberg (1987) 
o Vidal de Battini (1964) también identifican esta voz como una de las tantas aportadas por los inmigrantes al repertorio del habla familiar que se habrían extendido al uso general.

\section{Su uso en el Río de LA PLATA}

Los diccionarios generales y regionales consultados coinciden en situar el empleo de pibe con la acepción de 'niño' o 'muchacho' en Argentina y Uruguay. Como mencionamos, la edición del año 2014 del Diccionario de la Real Academia Española detalla su uso también en Bolivia y España. Respecto a este último país, se aclara que se trata de un uso jergal. Alvar (1992) en $E l$ diccionario general de la lengua española restringe el ámbito de uso al Río de la Plata. Por otro lado, Morinigo (1998) en su Diccionario de americanismos incluye otros países hispanoamericanos como Chile y Paraguay. Finalmente, Arias de la Cruz (1980) en su Diccionario temático de americanismos extiende el uso de pibe como 'niño' o 'muchacho' para toda Hispanoamérica.

Argentina no es mencionada como un lugar de uso para esta voz en el Diccionario de americanismos. Suplemento. Tomo II de Augusto Malaret (1942): allí, se restringe el uso de pibe a Uruguay y Bolivia, mientras que piberio sería exclusivo de Argentina. En las obras lexicográficas de argentinismos esta voz está registrada tempranamente. Así, en 1910, surge el Diccionario argentino de Tobías Garzón ${ }^{1}$, que incluye dos acepciones de

1 Lauría señala que esta publicación aparece durante el Centenario de la Revolución de Mayo "en plena euforia de exaltación nacional" junto con otros diccionarios de argentinismos como el Diccionario de argentinismos, neologismos y barbarismos (1911) de Lisandro Segovia, el Vocabulario 
pibe en su artículo: "PIBE. s. m. fam. Arg. Niño, pequeño // fam. Arg. Mozo, joven bochinchero ó informal, que no guarda la circunspección debida" (Garzón, 1910, 379). Se indica, en primer lugar, el carácter designativo para referirse a un niño, mientras que la segunda acepción da cuenta de su uso para jóvenes con un matiz peyorativo: "que no guarda la circunspección debida". En los dos casos, se aclara que se trata de formas empleadas en la Argentina.

Sin embargo, el testimonio más antiguo del uso de esta palabra en el Río de la Plata corresponde al ya citado "Diccionario Lunfardo - Lunfardo" publicado en 1894, en El idioma del delito por Antonio Dellepiane junto con otros términos del lunfardo, considerados como jerga delictiva. Esta temprana inclusión de pibe dentro del léxico lunfardo se mantendrá poco más de un siglo después, cuando en 1998 Conde incluya este término dentro del ya citado Diccionario etimológico del lunfardo: "pibe. m. Niño, joven. / 2. Fórmula de tratamiento afectuosa (dados ambos por el DRAE²). / 3. Hijo, gralmente. precedido por el adjetivo posesivo. // ESTAR HECHO UN PIBE: parecer más joven de lo que se es. (Del gen. pivetto - derivado a su vez del ital. jergal pivello-: nińo.)" (Conde, 2011, 351).

En su prólogo, ese autor señala que el artículo de este ítem lexical fue realizado a partir del Diccionario de la lengua española (Conde, 2011, 12) de

argentino (1911) de Diego Díaz Salazar y el proyecto inacabado de un Diccionario de argentinismos de la Academia Argentina de Lengua (1910). Para la autora, estas obras "si bien conservan el perfil subalterno respecto del DRAE, se caracterizan por representar un gesto central de intervención estatal que se propone recorrer el territorio de la lengua en su especificidad" (72, 2015).

2 El autor con esa sigla se refiere al Diccionario de la lengua española de la Real Academia Española. 
donde toma las dos primeras acepciones para agregar una tercera y una frase coloquial. El gesto de señalar en la propia entrada de la palabra la inclusión de pibe en el principal diccionario académico del español es coherente con su propuesta de demostrar la generalidad del léxico lunfardo en el Río de la Plata. Por este motivo, el autor argumenta en contra de quienes lo conciben como una jerga delictiva y señala que esta observación corresponde a la mirada de sus primeros compiladores, como el citado Dellepiane.

Recién en el año 1984 pibe tuvo su entrada en el Diccionario de la lengua española. Pebete había sido incluido años antes, a pesar de observaciones como las Teruggi $(1979,14)$ quien seńaló oportunamente la mayor amplitud del uso de pibe frente a pebete. El Diccionario de la lengua española indica las dos acepciones tomadas por Conde: "pibe, ba. De pebete. 1. m. y f. coloq. Arg., Bol. y Ur. Niño o joven. En Esp., u. c. jerg. 2. m. y f. coloq. Arg. y Bol. U. como fórmula de tratamiento afectuosa." (Real Academia Espańola, 2014). La primera acepción refiere al carácter designativo que este término tendría en el habla coloquial de Argentina, Bolivia y Uruguay, y en el uso jergal de España, mientras que la segunda acepción tendría lugar únicamente en Argentina y Bolivia.

Las obras lexicográficas de la Argentina se caracterizan por definir esta palabra a partir de los sinónimos del español general niño y joven. En el Diccionario del español del Uruguay de la Academia Nacional de Letras pibe es definido a partir del uruguayismo gurí "pibe, -a. (Del genov. pivetto, muchachito). m. y f. esp. gurí, -sa (1). // 2. m. y f. gurí, -sa (2). // 3. m. y f. obs. esp. gurí, - sa (3). // 4. f. obs. esp. gurí, -sa (5)" (Academia 
Nacional de Letras, 2011, 298). Esta observación nos permite trazar una diferencia entre el empleo de este término en Uruguay y Argentina: mientras que en la obra lexicográfica de consulta del Uruguay pibe es traducido a gurí, en la Argentina, el significado de pibe no necesita ser explicado por otro término percibido como más propio. La relación entre los artículos de pibe y gurí en este diccionario consiste en vincular a pibe cuatro acepciones de gurí. En Uruguay, pibe se emplearía como 'niño', 'muchacho', 'hijo' y 'novio'.

En el Diccionario del habla de los argentinos de la Academia Argentina de Letras, la primera acepción de pibe es presentada con su carácter designativo pero se agrega entre paréntesis una voz del habla coloquial peninsular: chaval: "pibe, ba. m y f. coloq. Niño o joven (chaval)." (Academia Argentina de Letras, 2008, 502). Esta definición insiste sobre el carácter coloquial dentro del habla de Argentina.

Dentro de este país, este término está asociado al habla de Buenos Aires. En El español de la Argentina de 1964, Vidal de Battini consigna la voz pibe entre las interjecciones del habla "popular y corriente de Buenos Aires" y destaca "la gran amplitud" (171) del uso de este término como fórmula de tratamiento. Sin embargo, hay que destacar el carácter influyente del habla porteña hacia el resto del país y, con ella, el vocabulario del lunfardo, en donde se podría incluir pibe. En este sentido, limitar el uso de pibe al espacio de Buenos Aires resulta insuficiente puesto que debemos tener en cuenta la difusión de este repertorio léxico a través del tango, la literatura y los medios de comunicación. 


\section{¿UN ARGENTINISMO EN ESPAÑA?}

Como señalamos anteriormente, el artículo del Diccionario de la lengua española indica el uso jergal de pibe en España. Se trata del uso con idéntica acepción a la que encontramos en Argentina, que tiene lugar en Canarias y que Beatriz Gómez Pablos (1999) ha explicado a través de la reconstrucción de la etimología del término en correlación con pebete en su artículo ya citado.

Para esta autora, la presencia de pibe en la península se explica por el regreso eventual o definitivo de inmigrantes canarios que habrían llevado este término del lunfardo porteño. Gómez Pablos basa su explicación adscribiéndose a la tradición de investigadores que ven en pibe un italianismo (Fontanella de Weinberg, Gobello, Teruggi, Vidal de Battini y Wagner) y argumentando contra quienes derivan esta voz de pebete como antífrasis de su significado primitivo (Corominas, Ambruzzi). De hecho, Gómez Pablos destaca que pibe no podría ser un derivado de pebete puesto que en Canarias este término resulta desconocido y, por lo tanto, constituye una excepción a la uniformidad de la distribución regional de pibe y pebete en Argentina y Uruguay.

\section{¿ARGENTINISMO O LUNFARDISMO?}

Entre los argumentos para descartar del origen italiano de pibe, Corominas señala que:

se emplea tanto (en el Interior) como en la capital, no tiene el menor matiz jergal en parte alguna, y ni siquiera es despectivo ni vulgar: aun 
gente distinguida lo emplea hablando de chicos o niños de buena familia y en tono meramente objetivo. (...) Es inverosímil que un vocablo tan arraigado y único en el habla de la familia argentina proceda de "centros populares italianizantes": tales vocablos son entonces lunfardos, o bien quedan restringidos a familias italianas o emparentadas con italianos" (Corominas, 1954, 447).

Esta observación sobre el uso de pibe en el habla general del país implica una contradicción entre argentinismo y lunfardismo, que tiene como presupuesto la equiparación de italianismo a lunfardismo, sin considerar que este repertorio léxico comprende voces de otros orígenes. Por otra parte, supone que el lunfardo únicamente circula en sectores de baja extracción social y que el hecho de que se emplee un término para "niños de buena familia” pareciera ser motivo para descartarlo como lunfardismo. Conviene, entonces, recuperar la definición que presenta Gobello en el prólogo de su Nuevo diccionario de lunfardo:

El lunfardo es, a mi entender (...) un repertorio de términos traídos por la inmigración (...) asumidos por el pueblo bajo de Buenos Aires, en cuyo discurso se mezclaban con otros de origen campesino, y quechuismos y lusismos que corrían ya en el habla popular, conformando un léxico que circula ahora en todos los niveles sociales de las "repúblicas de la Plata" (Gobello, 1999, 8. Las cursivas son mías).

Desde esta perspectiva, pibe podría haber tenido un origen lunfardo en el habla familiar de los inmigrantes italianos y extender su uso a otros sectores sociales. Este fenómeno de extensión puede haber motivado su reconocimiento como argentinismo a principios de siglo XX y su consecuente inclusión en el citado Diccionario argentino de Tobías Garzón. Según Gobello, 
esta ampliación en el uso forma parte de la definición del lunfardo y de ninguna manera implica su automática exclusión de este repertorio léxico. Si atendemos a esta salvedad en la definición, podría explicarse el hecho de que pibe haya continuado observándose como lunfardismo años luego de su incorporación en el Diccionario argentino en 1910. Testimonio de este hecho es su presencia en todos los diccionarios de lunfardo posteriores a esta fecha.

El hecho de que la literatura argentina del siglo XX haya incorporado lunfardismos para recrear el habla coloquial da cuenta de esta extensión. Así lo seńala Oscar Conde en "El lunfardo en la literatura argentina":

los lunfardismos no son solamente parte del habla. La mayoría de ellos posee ya registro literario. En la medida en que nuestros escritores, al menos los residentes en el Río de la Plata, se propongan imitar el habla de su tiempo, todas estas palabras seguirán apareciendo en sus obras tal como ya es habitual que aparezcan diariamente en los distintos medios de comunicación (Conde, 2010).

La presencia de pibe en la lengua escrita literaria se volverá más visible hacia la década de 1930. No es frecuente su aparición en la literatura de finales de siglo XIX y de la primera mitad del siglo XX. De hecho, Tobías Garzón no incluye referencias literarias en su entrada de pibe, como sí lo hace con otras voces.

Uno de los pocos testimonios de este período es el título de la obra de teatro de González Castillo publicada en el año 1906: El retrato de un pibe. Al interior de la obra, en lugar de pibe encontramos pebete. Este aspecto nos permite pensar, por un lado, en la identificación entre pibe y pebete, como registros de la evolución fonética que resultaría en ambos 
términos. Apenas unos años antes, Dellepiane había publicado ambas palabras en una misma entrada junto con otras posibles realizaciones. En la obra de González Castillo se asocia el uso de pibe/pebete al ámbito de la inmigración italiana pero sin matiz peyorativo de ningún tipo sino que atestigua su uso como 'hijo'.

Hacia finales de la década de 1920 se intensificará su uso en la literatura. En 1926, Roberto Arlt publica El juguete rabioso, donde observamos pibe, en primer lugar, con valor designativo para referirse a niño "-Sí, me acuerdo. Yo era un pibe" (Arlt, 1926, 195), dice el Rengo al recordar el pasado. Por otro lado, podemos encontrar su uso con mayúsculas como apodo de uno de los personajes: "lo llamé al Pibe" (Arlt, 1926, 193).

El juguete rabioso es una novela de aprendizaje en donde el protagonista, un nińo, recorre diversos escenarios urbanos en su ingreso al mundo de los adultos. En su obra, pibe se integra al repertorio lunfardo en la voz del narrador y de los personajes. Así, en una de sus crónicas que componen las Aguafuertes había dicho: "Escribo en un "idioma” que no es propiamente el castellano, sino el porteño" (1928, 373). En la literatura de Arlt, la inclusión de voces del lunfardo forma parte de la puesta en escena de un lenguaje que se percibe como más propio del espacio urbano emergente.

"No hay término lunfardo que no sea a la vez literario y coloquial", señala Gobello $(1999,10)$ al explicar su decisión de descartar la categoría lenguaje literario en la clasificación de sus artículos. Así, observamos que los ejemplos literarios citados corresponden a obras que, al intentar representar el habla coloquial urbana, incluyen términos del lunfardo. 
Esta presentación del lunfardo como un fenómeno que desde sus orígenes tuvo un nivel amplio de difusión en la sociedad porteña y que, por lo tanto, permite recrear su habla coloquial, constituye una revisión de la postura que adoptaron sus primeros descriptores. Como señala Conde $(2015,22)$ en la introducción a La muerte del pibe Oscar, "Lugones, 1879; Drago, 1888; Dellepiane, 1894; Carrizo -seudónimo de José S. Álvarez, más conocido como Fray Mocho-, 1897; Villamayor, 1915), todos ellos criminalistas o policías, (...) concibieron este vocabulario como patrimonio exclusivo de los malvivientes, esto es, como tecnolecto de la delincuencia". Para ese autor, la presencia de términos de la jerga delictiva en La muerte del pibe Oscar -publicada en 1926 al igual que El juguete rabioso- no debe llevar a la confusión de observar el lunfardo como léxico carcelario. Como señala el propio Conde $(2015,29)$, el interés lingüístico de este texto radica en la coexistencia de dos vocabularios que son distintos entre sí. En esta conjunción, el uso valorativo de pibe junto al nombre de pila adquiere, dentro del texto, la función de remarcar la juventud del personaje al momento de iniciarse en la vida delictiva. Esta caracterización forma parte de una doble estrategia para explicar su conducta: por un lado, se señala que su voluntad de imponerse a los demás era parte de su personalidad y que, por lo tanto, se había manifestado desde muy pequeño:

Desde chicuelo, en el conventillo donde aprendiera a "gatear" y a hurtarle las frutas o verduras de la $[\mathrm{s}]$ canastas al vendedor ambulante que ofrecía su carga apetitosa de puerta en puerta a los habitantes del "convento" cuando apenas contaba seis años y como su fuerte musculatura se lo permitía, al par que por su genio vivaracho, alegre, atrevido y sin miedo se imponía a 
su demás compańeros de juegos infantiles, pues en cuanto lo contrariaban los cacheteaba sin piedad o los "arranyaba" con lo primero que encontraba a mano, supo destacar su ínfima [sic] personalidad, fue temido y respetado (Villamayor, 2015, 215).

Por otro lado, esta caracterización permite al narrador insistir en la responsabilidad del sistema penitenciario en la formación de este joven como delincuente que, lejos de ofrecerle contención y educación, solo lo alienta a perfeccionar el obrar delictivo. De este modo, el imaginario infantil y de juventud que instala el uso de pibe, junto con términos como purrete o chicuelo, permite, dentro de esta novela, aportar una dimensión de ternura (Conde, 2015) que contrasta con las acciones delictivas del "Pibe Oscar".

En este sentido, la obra de Villamayor ofrece testimonio no solo del uso junto al nombre propio y de su productividad para conformar locuciones como "pibe rana", sino también de la presencia de estos usos en relación al léxico carcelario. En este sentido, cabe señalar que el uso de pibe para integrar el alias de un delincuente será cristalizado en la figura de Rogelio Gordillo (1910-1937), conocido como "Pibe Cabeza". Considerado una de las “celebridades del crimen" (Caimari, 2012, 43), el alias de Gordillo dará título a la película de Leopoldo Torre Nilsson en 1975.

De este modo, se pueden encontrar en estos testimonios de vinculación de pibe al léxico carcelario posibles antecedentes del actual pibe chorro, cuya presencia es atestiguada en la crónica periodística Cuando me muera quiero que me toquen cumbia. Vidas de pibes chorros de Cristian Alarcón publicada en el año 2003. Allí se observa que, en la actualidad, pibe forma parte 
de la variedad carcelaria tumbera a través de pibe chorro ${ }^{3}$. En esta nueva voz observamos la productividad de pibe para formar parte -junto con el lunfardismo chorro $^{4}$ - de un nuevo término que designaría a un estereotipo de joven delincuente procedente de sectores vulnerables de la sociedad. Los medios de comunicación sensacionalistas hicieron eco de este término en sus titulares: "Pibe chorro muestra lo robado y se ríe de los laburantes" (Grupo Crónica, 2016).

La popularización de pibe chorro se debe al grupo de cumbia villera Los pibes chorros fundado en el año 2000, cuyas canciones narran la vida cotidiana de estos jóvenes:

Llegamos los pibes chorros queremos las manos de todos arriba/ porque al primero que se haga el ortiba por pancho / y careta le vamos a dar. / Aunque no nos quieran somos delincuentes/ vamos de cańo con antecedentes robamos blindados, /locutorios y mercados no nos cabe una estamos re jugados. / Vendemos sustancia y autos nos choreamos hacemos / de primeras salideras en los bancos somos / estafadores piratas del asfalto todos nos conocen / por los reyes del afano. (Salinas, Kirovsky y Horro, 2002).

Debemos advertir que esta productividad de pibe junto a un adjetivo para cristalizar tipos sociales se hace presente en otros ejemplos de la cumbia villera. Así, podemos encontrar títulos de canciones como "El pibe tuerca"

3 No se encontraron artículos en los diccionarios consultados en donde se incluya pibe chorro en las entradas pibe o chorro.

4 CHORREAR. Lunf. Robar (“...pa’ que yo chorree/ toda la nobleza que esconden en su alma”. Linyera, ¡Semos...., 16). Del caló, chorar: robar. Chorro: ladró ("Yo soy Yhony pa él, pa los otros y pa cuanto chorro otario hay en el mundo!". Vacarezza, Los escrushantes, 11) Chorreo: práctica del robo. Chorizo: ladrón (por juego paronomástico con el esp. chorizo: embutido). En el leng. prevalecen las formas chorear, choro y choreo (Gobello, 1999, 88). 
(Salinas y Kirovsky, 2003), para hablar del ladrón de autopartes o "El pibito ladrón” (Salinas, Kirovsky, Horro y Macrini, 2002), que designaría a un pibe chorro de menor edad. Sin embargo, los ejemplos no se restringen al ámbito delictivo sino que también podemos encontrar "El pibe tripa" (Salinas, Kirovsky, Horro y Macrini, 2003), que designaría al que presume de su popularidad.

Si bien pibe chorro designaría un individuo de sexo masculino, es posible citar registros de su empleo con la variación de cambio de morfema a femenino: "Pescador persiguió y mató a piba chorra" (Télam, 2016) o "Piba chorra" de Guaymallén fue demorada por mostrar fotos con armas" (Otamendi, 2016).

\section{DE PIBE A PIBITO}

Vidal de Battini (1964) advirtió la generalización de pibe hacia individuos de mayor edad: "Pibe (italianismo) que comenzó a aplicarse a niños, en la actualidad ha alcanzado gran amplitud en el habla popular y corriente de Buenos Aires y se aplica a jóvenes y hasta a hombres" (Vidal de Battini, 1964, 171).

Si recuperamos el artículo de esta palabra en el Diccionario argentino de Tobías Garzón (1910, 379), observamos que allí ya se consignaba una segunda acepción que amplía el rango etario de esta voz aunque guarda un matiz despectivo: "PIBE. s. m. fam. Arg. Niño, pequeño // fam. Arg. Mozo, joven bochinchero ó informal, que no guarda la circunspección debida”. 
Incluso, si revisamos el "Diccionario Lunfardo - Español" de Dellepiane advertimos que la primera definición que encontramos no es "niño" sino "muchacho": "Muchacho, menor de edad, pilluelo (...)" (Dellepiane, 1894, 91). En esta obra lexicográfica, se consigna el repertorio del lunfardo en tanto términos pertenecientes a la jerga delictiva.

También Corominas (1954) repara en el hecho de que cuando pibe está dirigido a mayores adquiere un matiz despectivo: "se ha extendido a edades algo mayores, aunque no se dice ya de los que tienen más de 3-4 años, a no ser que se le dé carácter valorativo, en el sentido de 'mocoso, chico que quiere pasar por adulto', que entonces se podrá aplicar a adolescentes” (Corominas, 1954, 447).

La información que aportan estos artículos de diccionario permite precisar la observación que realiza Vidal de Battini en su publicación. La tendencia ampliatoria del término pondría de manifiesto, en realidad, la pérdida del matiz peyorativo que estaba asociado a esta voz cuando era empleada para referirse a jóvenes.

En la actualidad, es común escuchar entre los hablantes de la Ciudad de Buenos Aires el uso de este término para referirse a adolescentes, y en pocas ocasiones a hombres, aunque compite con otra voz como chabón, que está plenamente identificada con adolescentes o adultos de sexo masculino. Pibe muestra el matiz de "juventud" en una frase coloquial como Está hecho un pibe para decir que alguien no ha envejecido (Academia Argentina de Letras, 2018, 502). En este sentido, se observa que frente a la extensión de pibe para referirse a adolescentes, el diminutivo pibito cobra fuerza para 
enfatizar que se trata de un niño y no de un joven, como se observa en el título de la canción "El pibito ladrón".

\section{LOS PIBES}

La tendencia ampliatoria de pibe se observa en el uso actual del plural definido los pibes para referirse a la generación de jóvenes. Este uso encuentra testimonios en uno de los estribillos que los hinchas de fútbol en la Argentina dedican a los jugadores de las ligas juveniles: "Vamos, vamos los pibes" (Mauri, 2008).

En las generaciones más jóvenes, esta forma de plural definido también se utiliza para referirse al grupo al que el joven o adolescente pertenece, ya sea porque está unido afectivamente (grupo de amigos) o porque se considera parte en términos generacionales. Así, en las canciones de Wos, cantante de trap y rap nacido en el año 1998 y de amplia popularidad entre esas generaciones, se observa el uso del plural definido de pibe: "Fuera la yuta que meten al barrio / Le tira a los pibes y le mata los sueños" (Oliva y Yalve, 2019). En este ejemplo, el plural de pibe es utilizado como parte de un reclamo frente a la actuación de la policía, que es vista por el cantante como abusiva.

Asimismo, el cantante de rap Emanero (1987) emplea los pibes en un contexto que también constituye un reclamo social: “Tengo, tanto tiempo rapeando que sueño canciones cuando estoy durmiendo,/ entretengo al que quiere pensar más allá del mensaje que venden los medios,/ tengo algo que 
no se compra y solo se consigue con tiempo,/ y vos no le vendas más de droga a los pibes que están enroscados y se están muriendo" (Giannoni, 2018). En esta estrofa de la canción "XXXI", el reclamo está dirigido a los medios de comunicación y a quienes promueven las adicciones entre los jóvenes. De este modo, se observa que el plural se utiliza para realizar un reclamo respecto de una acción que se describe perjudicial para la juventud en su conjunto.

La presencia del plural definido de pibe en canciones de trap y rap permite observar la tendencia ampliatoria del término en un contexto juvenil, en donde esta voz aparece junto a otras propias del léxico adolescente actual como haters (Giannoni, 2018). A diferencia de esta última, la forma los pibes no aparece como exclusiva de esta jerga sino que puede ser utilizada por mayores para referirse a esta generación. Así, Alberto Sileoni, ministro de educación de la Argentina entre los años 2009 y 2015, se refirió a los jóvenes en estos términos durante una entrevista al diario Página 12: "actualmente la escuela no comprende la cultura de los pibes" (Carabajal, 2015). El empleo del plural de pibe en este caso tiene como objetivo mostrar cercanía con los adolescentes sin utilizar un término que pueda resultar despectivo o ser visto como exclusivo de esa generación.

\section{CONCLUSIONES FINALES}

A partir del análisis de la presencia de la palabra pibe en un conjunto de obras lexicográficas, medios gráficos y producciones culturales, se extrae, en primer lugar, que la condición de lunfardismo de la palabra pibe no resulta 
excluyente de la extensión de su uso. Desde sus orígenes, el lunfardo tuvo un nivel amplio de difusión en la sociedad porteña que impide circunscribir alguna de sus piezas al léxico carcelario o a un determinado sector social. Esta extensión contradice uno de los argumentos de Corominas en contra de su posible etimología del italiano jergal. El autor había refutado este posible origen, puesto que había identificado esta palabra como de uso general y sin rasgos jergales.

En segundo lugar, el análisis realizado permite demostrar la productividad de esta voz para adquirir nuevos usos dentro de la variedad tumbera o el habla de las nuevas generaciones que luego son extendidos al habla general. Su vinculación con el léxico de la cárcel se registra de forma evidente en el uso de este término para acompañar el nombre de pila de delincuentes célebres como Pibe Oscar y Pibe Cabeza, y en la conformación de pibe chorro a principios del siglo XXI. Del mismo modo, si bien el uso del plural definido para referirse a la juventud es registrado en producciones culturales que son consumidas por las generaciones más jóvenes, no se cristaliza en un sector sino que el empleo plural del término con esta connotación también está habilitado a adultos que intentan referirse a la juventud de un modo que demuestre cercanía con este sector.

A partir de estas consideraciones, se concluye que, si bien la tendencia ampliatoria de esta palabra coincide con la pérdida de su matiz peyorativo cuando es empleada para referirse a jóvenes, este hecho no impide que nuevamente pueda ser objeto de apropiación dentro de la variedad tumbera o por parte de las nuevas generaciones. De hecho, el alcance amplio de pibe 
permite que estos nuevos usos se incorporen al habla general y se constituya como una opción para ser utilizada en una diversidad de contextos.

\section{REFERENCIAS BIBLIOGRÁFICAS}

Arlt, Roberto. “¿Cómo quieren que les escriba?”. In: Aguafuertes. Obras completas, Tomo 2. Buenos Aires: Losada, 1929, 371-373.

Arlt, Roberto. “La crónica n 231”. In: Aguafuertes. Obras completas, Tomo 2, Buenos Aires: Losada, 1928, 369-370.

Arlt, Roberto. El Juguete rabioso. Buenos Aires: Espasa Calpe, 1926.

Academia Argentina de Letras. Diccionario del habla de los argentinos. Buenos Aires: Emecé, 2008.

Academia Nacional de Letras. Diccionario del español del Uruguay. Montevideo: Ediciones de la Banda Oriental, 2011.

Alvar Ezquerra, Manuel. El diccionario general de la lengua española. Barcelona: Vox, 1992.

Ambruzzi, Lucio. "Miscelánea”. In: Revista de filología española, Tomo XXIII, 1936. 67-68.

Arias de la Cruz, Miguel. Diccionario temático de americanismos. Madrid: Editorial Everest, 1980.

Caimari, Lila. "Pistoleros". In: Mientras la ciudad duerme. Pistoleros, policías y periodistas en Buenos Aires, 1920-1945. Buenos Aires: Siglo XXI, 2012, 28-58.

Carabajal, Mariana. "No es de calidad un sistema educativo con menos alumnos". Entrevista a Alberto Sileoni. In: Página 12, 13 de noviembre de 2015. Disponible en: https://www.pagina12.com.ar/diario/elpais/1-286037-2015-11-13.html. Último acceso: 14 de mayo de 2020. 
Conde, Oscar. Diccionario etimológico del lunfardo. Buenos Aires: Taurus, 2011.

Conde, Oscar. "El lunfardo en la literatura argentina". In: Gramma, Vol. XXI, No 47, 2010. Disponible en: http:// p3.usal.edu.ar/index.php/gramma/article/ view/59/122. Último acceso: 22 de enero de 2020.

Conde, Oscar. "Introducción". In: Villamayor, Luis Contreras. La muerte del Pibe Oscar. (Célebre escrushiante). Conde, Oscar (ed.) Buenos Aires: UNIPE, Editorial Universitaria, 2015.

Corominas, Joan. Diccionario crítico etimológico. Castellano e hispánico. Madrid: Gredos, 1954.

Dellepiane, Antonio. "Diccionario Lunfardo - Español”. In: El idioma del delito. Buenos aires: Arnoldo Moen Editor, 1894, 53-104.

Fontanella de Weimberg, María Beatriz."El español bonaerense”. In: El español de la Argentina y sus variedades regionales. Buenos Aires: Edicial, 1987, 37-60.

Grupo Crónica. "Pibe chorro muestra lo robado y se ríe de los laburantes". In: Crónica. Buenos Aires, 24 may. 2016. Disponible en: http://www.cronica. com.ar/article/details/63505/pibe-chorro-muestra-lo-robado-y- se-rie-de-loslaburantes. Último acceso: 20 de junio de 2017.

Garzón, Tobías. Diccionario argentino. Barcelona: Comisión Nacional del Centenario de la Revolución de Mayo y de la Universidad Nacional de Córdoba, 1910.

Giannoni, Federico. [Emanero]. (2018, 5 de diciembre). XXXI [Archivo de video]. Disponible en: https://www.youtube.com/watch?v=x6bQR7mEcQA\&vl=es-419. Último acceso: 14 de mayo de 2020.

Gobello, José. Nuevo diccionario del lunfardo. Buenos Aires: Corregidor: Buenos Aires, 1999.

Gómez Pablos, Beatriz. “¿Un lunfardismo en Canarias? Algunas observaciones sobre la etimología de pibe”. In: Verba Hispanica, Vol 8, No 1, 1999. Disponible en: 
http://revije.ff.uni-lj.si/VerbaHispanica/ article/view/6067. Último acceso: 20 de enero de 2020.

González Castillo, José. El retrato de un pibe. Buenos Aires: Losada, 1906.

Lauria, Daniela. "La lengua diccionarizada: Notas sobre la producción lexicográfica del español de la Argentina”. El Toldo de Astier, 6 (11), 69-77, 2015. En Memoria Académica. Disponible en: http://www.memoria.fahce.unlp.edu.ar/art_revistas/ pr.6946/pr.6946.pdf.

Mauri, Claudio. "Vamos, vamos los pibes". In: La Nación, 30 de septiembre de 2008. Disponible en: https://www.lanacion.com.ar/deportes/futbol/vamosvamos-los-pibes-retrato-del-futbol-argentino-nid1054773. Último acceso: 22 de mayo de 2020.

Malaret, Augusto. Diccionario de americanismos. Suplemento. Tomo II. Buenos Aires: Academia Argentina de Letras, 1944.

Morinigo, Alberto. Diccionario de americanismos e indigenismos. Buenos Aires: Claridad, 1998.

Oliva, Valentín; Yalve, Facunto [WOS DS3]. (2019, 9 de agosto) Canguro [Archivo de video]. Disponible en: https://www.youtube.com/watch?v=15QAOvBqT3c. Último acceso: 14 de mayo de 2020.

Otamendi, Leonardo. "Piba chorra" de Guaymallén fue demorada por mostrar fotos con armas. In: Mendozapost. Mendoza, 18 oct. 2016. Disponible en: http://www.mendozapost.com/nota/47017-piba-chorra-de-guaymallen-fuedemorada-por-mostrar-fotos-con-armas/. Último acceso: 20 de enero de 2020.

Real Academia Española (2014). Diccionario de la lengua española. Edición online. Disponible en: http://www.rae.es/ Último acceso: 20 de enero de 2020.

Salinas, Ariel David y Kirovsky, Norberto Claudio. "El pibe tuerca”. In: Criando cuervos, Warner Chappell Music, 2003. 
Salinas, Ariel David; Kirovsky, Norberto Claudio; Horro, Diego Carlos; Macrini, Diego Marcelo. "El pibito ladrón", Solo le pido a Dios. Warner Chappell Music Argentina, 2002.

Salinas, Ariel David; Kirovsky, Norberto Claudio. "Llegamos los Pibes Chorros", Solo le pido a Dios. Warner Chappell Music Argentina, 2002.

Salinas, Ariel David; Kirovsky, Norberto Claudio; Macrini, Diego Marcelo. "El pibe tripa", En Vivo.... Hasta la muerte, s/d, 2002.

Télam. Pescador persiguió y mató a piba chorra. In: Crónica. Buenos Aires, 12 ene. 2016. Disponible en: http:// www.cronica.com.ar/article/details/52176/ pescador-persiguio-y-mato-a-piba-chorra. Último acceso: 20 de junio de 2017.

Teruggi, Mario E. Panorama del lunfardo. Génesis y esencia de las hablas coloquiales urbanas. Buenos Aires: Sudamericana, 1979.

Teruggi, Mario E. Diccionario de voces lunfardas rioplatenses. Buenos Aires: Alianza Editorial, 1998.

Vidal de Battini, Berta. El español de la Argentina. Estudio destinado a los maestros de las escuelas primarias. Buenos Aires: Ministerio de Educación de la Nación. Dirección General de Enseñanza Primaria, 1964.

Villamayor, Luis Contreras. La muerte del Pibe Oscar. (Célebre escrushiante). Conde, Oscar (ed.) Buenos Aires: UNIPE, Editorial Universitaria, 2015.

Wagner, Leopold. "Miscelánea”. En: Revista de filología española, Tomo XV, 1928, 193-194. 
